Abstracted/indexed in Academic Search Complete, Asia Journals Online, Bangladesh Journals Online, Biological Abstracts, BIOSIS Previews, CAB Abstracts, Current Abstracts, Directory of Open Access Journals, EMBASE/Excerpta Medica, Google Scholar, HINARI (WHO), International Pharmaceutical Abstracts, Open J-gate, Science Citation Index Expanded, SCOPUS and Social Sciences Citation Index;

ISSN: $1991-0088$

\title{
Fractionation and anti-inflammatory effects of polyphenol enriched extracts from apple pomace
}

\author{
Tianli Yue', Xuelian Bai', Huawei Zhang' and Yahong Yuan' \\ ${ }^{1}$ College of Food Science and Engineering, Northwest A \& F University, Yangling 712100, China; ${ }^{2}$ School of \\ Pharmaceutical Sciences, Zhejiang University of Technology, Hangzhou 310014, China.
}

\begin{tabular}{|c|c|}
\hline \multicolumn{2}{|l|}{ Article Info } \\
\hline Received: & 26 March 2011 \\
\hline Accepted: & 27 March 2011 \\
\hline Available Online: & 28 March 2011 \\
\hline \multicolumn{2}{|c|}{ DOI: 10.3329/bjp.v7i1.10194 } \\
\hline \multicolumn{2}{|c|}{$\begin{array}{l}\text { Cite this article: } \\
\text { Yue T, Bai X, Zhang H, Yuan Y. Frac- } \\
\text { tionation and anti-inflammatory ef- } \\
\text { fects of polyphenolenriched extracts } \\
\text { from apple pomace. Bangladesh J } \\
\text { Pharmacol. 2012; } 7: 28-32 \text {. }\end{array}$} \\
\hline
\end{tabular}

\begin{abstract}
Bioactive polyphenols are the predominant ingredients in apple pomace, an agro-industrial byproduct in apple juice processing. The present work focused on fractionation of ethanol extract of apple pomace using macroporous absorbent resin chromatography and HPLC analysis of all fractions recovered from polyphenol-enriched extract and their inhibitory effects on cyclooxygenase-2 (COX-2) expression in lipo-polysaccharides (LPS) -induced mouse RAW 264.7 cell line. Six fractions API-VI were achieved through fractionation eluting with aqueous alcohol. HPLC analysis indicated that APIII eluted by $40 \%$ ethanol had the highest content of total phenolics, which was $148.1 \pm 3.1 \mathrm{mg}$ gallic acid equivalents per $100 \mathrm{~g}$ of dry apple pomace. Anti -inflammatory assays showed that APIII had the strongest activity against COX-2 expression at $5 \mu \mathrm{g} \mathrm{mL}-1$ and procyanidin B2 and quercetin exhibited positive correlation with their anti-inflammatory effects. Our data suggested that phenolics could be prepared from apple pomace and applied in the management of inflammatory diseases.
\end{abstract}

\section{Introduction}

With an annual yield of over 3 million tons, China has become the world's largest producer of apple pomace (AP) since 2009. As an agroindustrial byproduct, apple pomace has caused many economical and environmental problems because of its extremely low protein content and high amount of sugar. In order to utilize this material, many studies had or have being carried out to generate value-added products, such as enzymes, single cell protein, ethanol, citric acids, aroma compounds, pigment, polysaccharides, pectins, mushrooms (Attri and Joshi, 2006; Rachana and Gupta, 2010; Shalini and Gupta, 2010; Vendruscolo et al., 2008). The recovery of apple polyphenols from pomace as an excellent healthcare product is another important biotechnological application (Bhushan et al., 2008). Biological assays showed apple polyphenols have a wide range of pharmacological effects, such as antibacterium (Pastene et al., 2009), antivirus (Suarez et al., 2010), anti-oxidant activity (Garcia et al., 2009), and the inhibition of colon carcinogenesis in vitro (McCann et al., 2007; Zessner et al., 2008). However, the anti-inflammatory effect of polyphenol-enriched fraction from apple pomace has not been reported till now.

Inflammation is a complex pathophysiological process mediated by a variety of signaling molecules produced by leukocytes, macrophages, and mast cells. Cyclooxygenase (COX), a crucial enzyme in the inflammatory process, plays a key role as a rate-limiting enzyme in the production of potent proinflammatory prostaglandins (PGs) biosynthesis, exists in at least two isoforms, designated as COX-1 and COX-2 (Lee and Kim, 2010). COX-1 is a housekeeping enzyme, being constitutively expressed in almost all mammalian tissues. In contrast, 
COX-2 is barely detectable under normal physiological conditions. However, it can be induced rapidly and transiently by pro-inflammatory mediators and mitogenic stimuli including cytokines, endotoxins, growth factors, oncogenes, and phorbol esters. So, COX-2 has received considerable attention for its potential role in the inflammation and disease development (Burnett et al., 2007; Kim et al., 2007).

The present work focused on fractionation of ethanol extract using column chromatography method and anti -inflammatory assay of the recovered fractions. Furthermore, phenlics compositions of fractions were analyzed by HPLC.

\section{Materials and Methods}

\section{Apple pomace}

Apple pomace used throughout this work was a mixture of juice-squeezed Fuji and Qinguan apples from Shaanxi Hengxing Fruit Juice Co., Ltd, the largest manufacturer of apple juice concentrate in China. The fresh apple pomace was dried in convection at $50^{\circ} \mathrm{C}$ until it reached a constant weight. After finely milled and sieved through a 20 mesh $(0.8 \mathrm{~mm})$ sieve, the samples were packed in plastic bags and stored at $-20^{\circ} \mathrm{C}$.

\section{Chemicals}

Nine polyphenol standards (chlorogenic acid, caffeic acid, syringin, procyanidins B2, (-)- epicatechin, cinnamic acid, coumaric acid, phloridzin, quercetin), gallic acid and Folin-Ciocalteu reagent were purchased from Sigma-Aldrich Chemical Co. (St. Louis, USA). Lipopolysaccharides (LPS) were Escherichia coli sero-type 0111:B4 from Sigma-Aldrich Chemical Co. (St. Louis, USA).

\section{Extraction of $A P$}

About $100 \mathrm{~g}$ pretreated apple pomace was extracted with a microwave experiment equipment (NJC 03-2, China) according to a previously published protocol (Bai et al., 2010). The afforded extract was concentrated under reduced pressure and lyophilized (Freezone 2.5 plus, Labconco, USA). After resolving in $500 \mathrm{~mL}$ of $20 \%$ ethanol solution, the resulting extract was centrifuged for $15 \mathrm{~min}$ at 10,000 rpm (CR21GII, Hitachi Koki Co., Ltd., Japan), and preserved at $4^{\circ} \mathrm{C}$. Fractionation of $A P$ : $200 \mathrm{~mL}$ of polyphenol-enriched extract was retained on $100 \mathrm{~mL}$ macroporous adsorbent resin XAD-16 (Rohm and Haas, PA, USA) and packed into a normal atmosphere column $(300 \times 30 \mathrm{~mm})$. AP were gradually eluted with three bed volumes of distilled water and aqueous alcohol, which concentrations were 20, 40, 60, 80 and $100 \%$, respectively. Six collected fractions, respectively named as API, APII, APIII, APIV, APV and APVI, were concentrated into $100 \mathrm{~mL}$ under reduced pressure (Eyela NC-2000, Tokyo, Japan) and preserved at $4^{\circ} \mathrm{C}$ until determination of total phenolics content and HPLC analysis.

\section{Determination of total phenolics content}

The total phenolic content of fraction was determined by the modified Folin-Ciocalteu method, following the procedure proposed by Wijngaard and Brunton (2010). Gallic acid as a standard was diluted with distilled water to give appropriate concentrations for a standard curve. $100 \mu \mathrm{L}$ of afforded fraction or gallic acid, $100 \mu \mathrm{L}$ of methanol, $100 \mu \mathrm{L}$ Folin-Ciocalteu reagent and $700 \mu \mathrm{L}$ of $\mathrm{Na}_{2} \mathrm{CO}_{3}$ were aliquoted into a $1.5 \mathrm{~mL}$ microcentrifuge tube. After immediate vibration and incubation in the dark for $20 \mathrm{~min}$ at room temperature, the samples were centrifuged at 13,000 rpm for 3 min (Hitachi Koki Co., Ltd., Japan). The absorbance of the supernatant was then measured at $735 \mathrm{~nm}$ in $1 \mathrm{~mL}$ plastic cuvettes using a spectrophotometer (1700 Pharma Spec, Shimad$\mathrm{zu}$, Japan). The results were expressed as mg gallic acid equivalent per $100 \mathrm{~g}$ of dry apple pomace (mg GAE/ $100 \mathrm{~g}$ ). Triplicate tests were conducted for each sample.

\section{Phenolic composition analysis}

HPLC analysis of AP was carried out on a Shimadzu system series LC-10Avp (Toyko, Japan) equipped with a Class VP chromatography data station software, a SIL -10AF autosampler, a CTO-10AS column oven $\left(25^{\circ} \mathrm{C}\right)$, and a SPD-10AV UV-Visible detector. Wavelength monitoring was performed at $280 \mathrm{~nm}$. Separation of polyphenols was carried out on a reversed phase Sunfire C8 $(250 \times 4.6 \mathrm{~mm}$ ID, $5 \mu \mathrm{m})$ (Waters Co., USA). The elution solvents consisted of $90 \%$ aqueous $0.1 \%$ acetic acid (solvent $\mathrm{A}$ ) and $10 \%$ acetonitrile (solvent $\mathrm{B}$ ). All solvents were filtered with a $0.45 \mu \mathrm{m}$ membrane filter before HPLC analysis. Flow rate was set at $1.2 \mathrm{~mL}$ min- 1 and the injection volume was $10 \mu \mathrm{L}$. Quantification of polyphenols was done by the external standard method. The phenolic level was expressed in $\mathrm{mg}$ per 1 $\mathrm{kg}$ of dry apple pomace (mg kg-1).

\section{Cell culture}

The mouse macrophage cell line RAW 264.7 was obtained from Cell Storehouse of Chinese Academy of Science (Shanghai, China) and grown in Dulbecco's modified Eagle's medium supplemented with $10 \%$ fetal bovine serum and 100 units mL-1 penicillin/streptomycin sulfate. The cells incubated in a humidified incubator with $5 \% \mathrm{CO}_{2}$ atmosphere at $37^{\circ} \mathrm{C}$ were fed with fresh medium every 2 days and subcultured when they reached a confluence of $80 \%$.

\section{COX-2 proteins assay of the cells}

After determination of total phenolic content and HPLC analysis, six fractions API-VI were lyophilized and dispersed in dimethyl sulfoxide $(5 \mu \mathrm{g} \mathrm{mL}-1)$. The mouse macrophage cell line RAW 264.7 cells pretreated with 
Table I

Mean content of total phenolics and phenolic compounds of fractions API-IV

\begin{tabular}{|lcccccc|}
\hline Compound & API & APII & APIII & APIV & APV & APVI \\
\hline Total phenolicsa & $52.9 \pm 3.2$ & $58.2 \pm 2.5$ & $148.1 \pm 3.1$ & $64.9 \pm 2.1$ & - & - \\
Chlorogenic acidb & $0.14 \pm 0.02$ & $0.31 \pm 0.03$ & $2.84 \pm 0.1$ & $1.90 \pm 0.1$ & - & - \\
Syringinb & $0.18 \pm 0.03$ & $0.23 \pm 0.02$ & $1.22 \pm 0.1$ & $0.14 \pm 0.01$ & - & - \\
Procyanidin B2b & $1.7 \pm 0.1$ & $2.6 \pm 0.2$ & $92.6 \pm 2.2$ & - & - & - \\
Caffeic acidb & - & $0.15 \pm 0.02$ & $0.13 \pm 0.01$ & $0.16 \pm 0.01$ & - & - \\
Cinnamic acidb & $0.88 \pm 0.1$ & $0.12 \pm 0.01$ & $0.19 \pm 0.02$ & - & - & - \\
Phlorizinb & - & $0.19 \pm 0.02$ & - & $0.18 \pm 0.02$ & - & - \\
Quercetinb & - & $5.5 \pm 0.2$ & $46.7 \pm 1.3$ & $19.6 \pm 0.5$ & - & - \\
Hyperinb & - & - & $1.5 \pm 0.11$ & $8.9 \pm 0.3$ & - & - \\
\hline
\end{tabular}

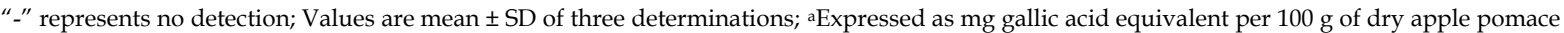
(mg GAE $100 \mathrm{~g}-1)$; b Expressed as mg per $1000 \mathrm{~g}$ of dry apple pomace (mg kg-1)

fractions API-VI respectively for 4 hours were treated with $1 \mu \mathrm{g}$ mL-1 of LPS for 20 hours. The cells in the control group were left untreated and in the LPS group were treated with LPS. After incubation, cells were harvested using a cell scraper and lysed in lysis buffer [20 mM Tris (pH 7.4), 5 mM EDTA, 0.1\% Triton X-100, and $0.01 \%$ 2-mercaptoethanol]. The lysates were sonicated and centrifuged at $15,000 \mathrm{rpm}$ for $10 \mathrm{~min}$ at $4^{\circ}$ $\mathrm{C}$ to remove insoluble material. The supernatant was transferred to a new tube and stored at $-20^{\circ} \mathrm{C}$ until western blotting analysis. The total protein concentration was measured by the Bio-Rad protein assay kit (Hercules, USA) using bovine serum albumin as the standard. Samples containing equal amounts of protein concentration were heated at $95^{\circ} \mathrm{C}$ for $5 \mathrm{~min}$, separated by $10 \%$ sodium dodecyl sulfatepolyacrylamide gel electrophoresis, and electrotransferred to nitrocellulose membranes at $10 \mathrm{~V}$ for 25 min using a semidry transfer (Bio-Rad Laboratories Ltd., USA). The membranes were blocked for 2 hours at room temperature with Tris-buffered saline containing 5\% non-fat milk, and were then incubated with anti-COX-2 antibody (diluted 1:1,000) (Santa Cruz Biotechnology, USA) for 4 hours at room temperature and subsequently with horseradish peroxidase-conjugated antigoat secondary antibody (diluted 1:2,500) (Santa Cruz Biotechnology, USA) for 1 hour at room temperature. Peroxidase activity was visualized using an ECL kit (Pierce, USA) and a-Tubulin was used as an equal loading control.

\section{Statistical analysis}

All data were expressed as means \pm SD from three independent experiments. Statistical significance was analyzed by Student's t-test and one-way analysis of variance (ANOVA) using SPSS Version 13.0. Values of $\mathrm{p}<0.05$ were considered to be statistically significant differences.

\section{Results}

Different phenols of ethanol extract from apple pomace were separated by absorbent resin column chromatography. Different phenolic compounds were eluted by different polar solutions. As shown in Table I, six fractions API-VI had different total phenolic contents. Among these fractions, APIII was found to have the highest content of total phenolic content (148.1 $\pm 3.1 \mathrm{mg}$ GAE 100g-1), followed by APIV $(64.9 \pm 2.1 \mathrm{mg}$ GAE 100g-1), APII (58.2 \pm 2.5 mg GAE 100g-1), API (52.9 $\pm 3.2 \mathrm{mg}$ GAE $100 \mathrm{~g}-1), \operatorname{APV}(10.4 \pm 1.2 \mathrm{mg}$ GAE $100 \mathrm{~g}-1)$ and APVI (10.0 $\pm 0.5 \mathrm{mg}$ GAE 100g-1).

HPLC analysis showed that polyphenols of API-VI had substantial variations in individual constituents (Table I). Especially, APIII had the highest concentrations of procyanidin B2 $(92.6 \pm 2.2 \mathrm{mg} \mathrm{kg}-1)$ and quercetin (46.7 $\pm 1.3 \mathrm{mg} \mathrm{kg}-1$ ), whereas its (-)-epicatechin and phlorizin were not detected. No (-)-epicatechin was found in fractions API-VI. The phenolic constituents of fractions APV and APVI were not detected.

Anti-inflammatory assay of fractions API-VI were carried out using western blotting analysis. As shown in Figure 1, murine RAW 264.7 macrophage cells expressed undetectable levels of COX-2 protein under unstimulated conditions. However, treatment with LPS led to a dramatic increase in COX-2 expression. Fractions API-VI had different inhibitory effects on the LPSinduced COX-2 expression, which only APIII had the significant inhibitory activity. Namely, APIII exhibited stronger anti-inflammatory effects than other fractions. It maybe suggested that total phenolic contents and/or constituents of fractions had correlation with their antiinflammatory effects.

In order to identify the potential contributor(s) of inhibiting COX-2 protein expression in polyphenolenriched 


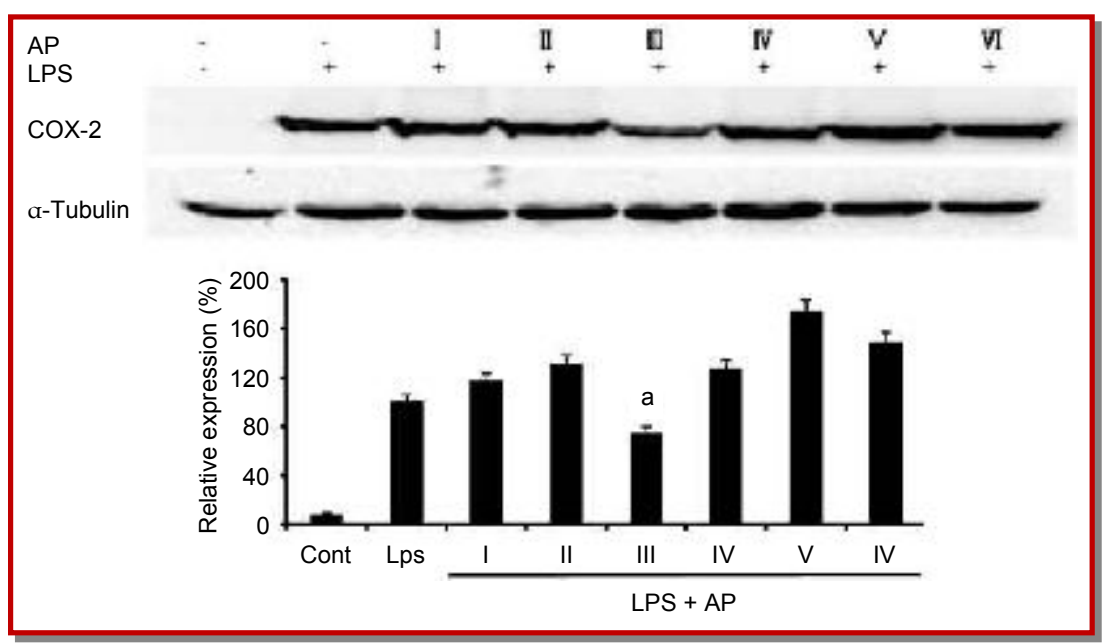

Figure 1: Effect of polyphenol-enriched fractions API-VI at $5 \mu \mathrm{g}$ mL-1 on COX-2 expression in LPS-induced RAW 264.7 macrophage cells. aSignificant difference: $\mathrm{p}<0.05$ as compared to the LPS-treated group

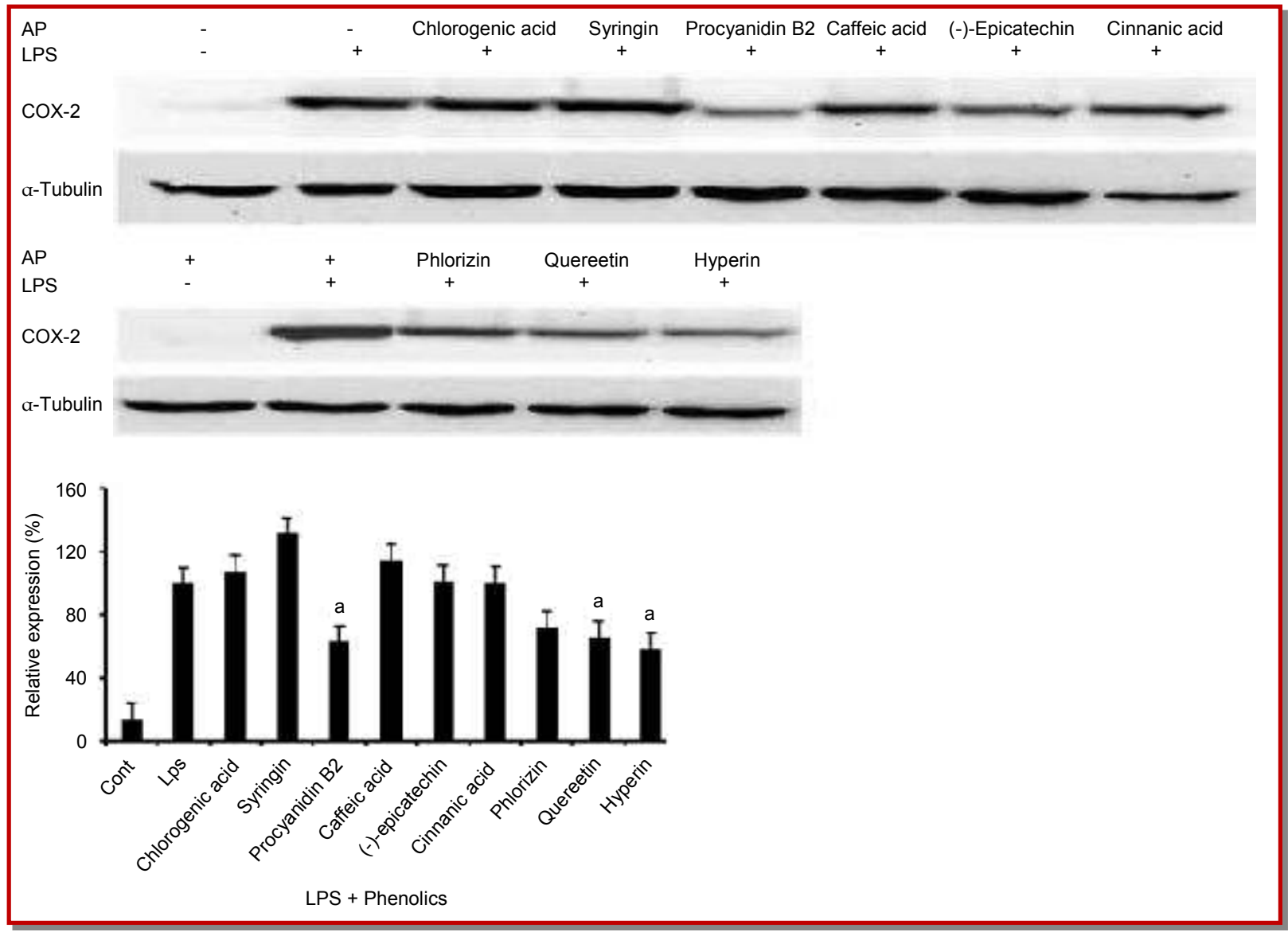

Figure 2: Effect of nine phenolics at $100 \mu \mathrm{M}$ on COX-2 expression in LPS-induced RAW 264.7 macrophage cells. aSignificant difference: $p<0.05$ as compared to the LPS-treated group

extract of apple pomace, nine phenolic standards were used to anti-inflammatory assay. After treatment with these phenolics $(100 \mu \mathrm{M})$ and LPS, cellular proteins were extracted and subjected to western blotting analysis of COX-2. As shown in Figure 2, pretreatment with phenolics caused a discrepancy in LPS-induced COX-2 expression. Procyanidin B2, hyperin and quercetin evidently reduced COX-2 expression level, which procyanidin B2 exhibited the strongest inhibitory activity at the same concentration. (-)-epicatechin, phlorizin and 
cinnamic acid showed no potent anti-inflammatory effects. On the contrary, chlorogenic acid, syringin and caffeic acid promoted COX-2 expression. The results indicated that procyanidin B2, hyperin, quercetin, (-)epicatechin, phlorizin and cinnamic acid had positive correlation with their COX-2 suppression, which was consistent with the previous reported findings (Zhang et al., 2006; Ying and Zhang, 2011). That was why APIII with the highest contents of procyanidin B2 and quercetin exhibited the strongest anti-inflammatory effects among six fractions.

\section{Discussion}

Six polyphenol-enriched fractions API-VI were purified from apple pomace using macroporous absorbent resin XAD-16 in the present work. Anti-inflammatory test showed that APIII had the stronger activity against COX-2 expression than any other fraction. HPLC analysis and bioassay suggested that different phenolic compound had different inhibitory effect on COX-2 expression. Procyanidin B2, hyperin and quercetin seem to play an important role in COX-2 suppression. Based on our findings, the inhibitory effect of ethanol extract from apple pomace on COX-2 suppression was correlated not only with its total phenolic content but also with its phenolic constituents. Therefore, fractionation of polyphenol-enriched extract from apple pomace using macroporous absorbent resins could be effective way to prepare anti-inflammatory natural products, which may be useful as a medicinal food.

\section{Acknowledgement}

We greatly acknowledge the financial support for this work from National Science Foundation of China (No. 31071550 and No. 81001381) and the research grant New Function Development of Valuable Instrument (No. dysb110105) from Northwest A \& F University, China.

\section{References}

Attri D, Joshi VK. Optimization of apple pomace based pigment production medium and fermentation conditions for by Chromobacter sp. J Food Sci Technol. 2006; 43: 484-87.

Bai XL, Yue TL, Yuan YH, Zhang HW. Optimization of microwave-assisted extraction of polyphenols from apple pomace using response surface methodology and HPLC analysis. J Sep Sci. 2010; 33: 3751-58.

Bhushan S, Kalia K, Sharma M, Singh B, Ahuja PS. Processing of apple pomace for bioactive molecules. Crit Rev Biotechnol. 2008; 28: 285-96.

Burnett BP, Jia Q, Zhao Y, Levy RM. A medicinal extract of Scutellaria baicalensis and Acacia catechu acts as a dual inhibitor of cyclooxygenase and 5-lipoxygenase to reduce inflammation. J Med Food. 2007; 10: 442-51.
Garcia YD, Valles BS, Lobo AP. Phenolic and anti-oxidant composition of by-products from the cider industry: Apple pomace. Food Chem. 2009; 117: 731-38.

Kim HG, Yoon DH, Kim CH, Shrestha B, Chang WC, Lim SY, Lee WH, Han SG, Lee JO, Lim MH, Kim GY, Choi S, Song WO, Sung JM, Hwang KC, Kim TW. Ethanol extract of Inonotus obliquus inhibits lipopolysaccharide-induced inflammation in RAW 264.7 macrophage cells. J Med Food. 2007; 10: 80-89.

Kumar D, Verma R, Bhalla TC. Citric acid production by Aspergillus niger van. Tieghem MTCC 281 using waste apple pomace as a substrate. J Food Sci Technol. 2010; 47: 458-60.

Lee JH, Kim GH. Evaluation of anti-oxidant and inhibitory activities for different subclasses flavonoids on enzymes for rheumatoid arthritis. J Food Sci. 2010; 75: H212-17.

McCann MJ, Gill CIR, O`Brien G, Rao JR, McRoberts WC, Hughes P, McEntee R, Rowland IR. Anti-cancer properties of phenolics from apple waste on colon carcinogenesis in vitro. Food Chem Toxicol. 2007; 45: 1224-30.

Pastene E, Speisky H, Troncoso M, Alarcon J, Figueroa G. In vitro inhibitory effect of apple peel extract on the growth of Helicobacter pylori and respiratory burst induced on human neutrophils. J Agric Food Chem. 2009; 57: 7743-49.

Shalini R, Gupta DK. Utilization of pomace from apple processing industries: A review. J Food Sci Technol. 2010; 47: 365-71.

Suarez B, Alvarez AL, Garcia YD, del Barrio G, Lobo AP, Parra F. Phenolic profiles, anti-oxidant activity and in vitro antiviral properties of apple pomace. Food Chem. 2010; 120: $339-42$.

Vendruscolo F, Albuquerque PCM, Streit F, Esposito E, Ninow JL. Apple pomace: A versatile substrate for biotechnological applications. Crit Rev Biotechnol. 2008; 28: 1-12.

Wijngaard $\mathrm{HH}$, Brunton $\mathrm{N}$. The optimisation of solid-liquid extraction of anti-oxidants from apple pomace by response surface methodology. J Food Eng. 2010; 96: 134-40.

Ying C, Zhang HW. Preparation of procyanidin B2 from apple pomace and its inhibitory effect on the expression of cyclooxygenase-2 in lipopolysaccharide-treated RAW264.7 macrophages. Bangladesh J Pharmacol. 2011; 6: 106-10.

Zessner H, Pan L, Will F, Klimo K, Knauft J, Niewohner R, Hummer W, Owen R, Richling E, Frank N, Schreler P, Becker H, Gerhauser C. Fractionation of polyphenolenriched apple juice extracts to identify constituents with cancer chemopreventive potential. Mol Nutr Food Res. 2008; 52: S28 -44 .

Zhang WY, Liu HQ, Xie KQ, Yin LL, Yi LI, Kwik-Uribe CL, Zhu XZ. Procyanidin dimer B2 [epicatechin-(4 $\beta-8)-$ epicatechin] suppresses the expression of cyclooxygenase-2 in endotoxin-treated monocytic cells. Biochem Biophys Res Commun. 2006; 345: 508-15.

Author Info
Yahong Yuan (Principal contact)
e-mail: baixl2007@nwsuaf.edu.cn

